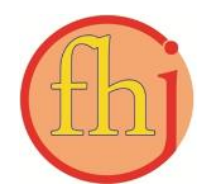

Faletehan Health Journal, 8 (3) (2021) 166-172

www. journal.Ippm-stikesfa.ac.id/ojs/index.php/FHJ

ISSN 2088-673X | e-ISSN 2597-8667

\title{
Perilaku Hidup Bersih dan Sehat melalui Upaya Pemberdayaan Masyarakat
}

\author{
Imelda Fitri ${ }^{1 *}$, Rifa Rahmi ${ }^{2}$, Hotmauli ${ }^{1}$ \\ ${ }^{1}$ Kebidanan, Fakultas Farmasi dan Ilmu Kesehatan, Universitas Abdurrab Pekanbaru \\ ${ }^{2}$ Kebidanan, STIKes Al-Insyirah Pekanbaru \\ *Corresponding Author: imelda.fitri@univrab.ac.id
}

\begin{abstract}
Abstrak
Data tiga tahun terakhir di Provinsi Riau menunjukkan bahwa pencapaian Perilaku Hidup Bersih Sehat (PHBS) selalu menjadi yang terendah. Tujuan penelitian ini adalah untuk mengetahui pengaruh pemberdayaan masyarakat berbasis keluarga melalui posyandu, kader, pengorganisasian/kelompok terhadap PHBS di TPA Muara Fajar Rumbai Pekanbaru. Desain penelitian adalah cross sectional. Sampel penelitian ini adalah 26 ibu rumah tangga di RT 01/RW 03 TPA Muara Fajar Rumbai Pekanbaru. Instrumen yang digunakan adalah kuesioner. Analisis data menggunakan uji korelasi Pearson dan uji regresi linear. Hasil penelitian menunjukkan bahwa pemberdayaan masyarakat berbasis keluarga melalui kader berpengaruh signifikan ( $p=0,0020)$ terhadap PHBS dan berpengaruh paling besar 0,2 kali $\left(r=0,455 ; R^{2}=0,207\right)$. Temuan tersebut dibandingkan dengan pemberdayaan masyarakat berbasis keluarga melalui posyandu dan pengorganisasian dengan besar pengaruh 0,123 kali $\left(r=0,348 ; R^{2}=0,121\right)$ dan 0,024 kali $\left(r=0,141 ; R^{2}=0,020\right)$. Masih ada masyarakat yang berada pada standar Sehat I (3,9\%) dan Sehat II $(7,7 \%)$.

Kata Kunci: Pemberdayaan Masyarakat Berbasis Keluarga, PHBS
\end{abstract}

\section{Clean and Healthy Living Behavior through Commmunity Empowerment}

\begin{abstract}
The data of Clean and Healthy Living Behavior (CHLB) in Riau Province in the last three years was always the lowest. The purpose of this study was to examine the influence of family-based community empowerment through integrated healthcare center (Ina. posyandu), the caders, the organizing or group on the CLHB at Muara Fajar Landfills, Rumbai, Pekanbaru. The research design was cross sectional. The samples were 26 housewives at RT 01/RW 03 of Muara Fajar Landfills, Rumbai, Pekanbaru. The research instrument was a questionaire. The data was analyzed by Pearson correlation and linier regression test. The results showed that family-based community empowerment through caders significantly influenced the clean and healthy living behavior ( $p$ value 0.0020$)$ and had the biggest influence 0.2 times $\left(r=0.455 ; R^{2}=\right.$ $0.207)$. The scores was compared to the family-based community empowerment through integrated health care center and the organizing which influence scores respectively were 0.123 times $\left(r=0.348 ; R^{2}=0.121\right)$ and 0.024 times $(r=0.141$; $\left.R^{2}=0.020\right)$. There were still community on health standard I (3.9\%) and and health standard II (7.7\%).

Keywords: Family-Based Community Empowerment, $\mathrm{CHLB}$
\end{abstract}


Faletehan Health Journal, 8 (3) (2021) 166-172

www. journal.Ippm-stikesfa.ac.id/ojs/index.php/FHJ

\section{Pendahuluan}

Kesehatan merupakan indikator keberhasilan pembangunan suatu bangsa, karena itu pembangunan kesehatan diarahkan untuk mencapai Indonesia sehat, berprilaku hidup bersih dan sehat, mempunyai akses terhadap pelayanan kesehatan serta memiliki derajat kesehatan yang setinggi-tingginya. Perilaku Hidup Bersih dan Sehat (PHBS) adalah sekumpulan perilaku yang dipraktikkan atas dasar kesadaran sebagai hasil pembelajaran, yang menjadikan seseorang, keluarga, kelompok atau masyarakat mampu menolong dirinya sendiri (mandiri) di bidang kesehatan dan berperan aktif dalam mewujudkan kesehatan masyarakat (Kemenkes RI, 2011). Adanya PHBS tatanan rumah tangga sehat dapat diwujudkan dengan perilaku sehat dan lingkungan sehat (Depkes, 2008).

Pencapaian PHBS di Indonesia sebelum masa pandemik Covid-19 masih tergolong rendah (Yuningsih, 2020). Berdasarkan data Riskesdas tahun 2017 persentase PHBS di Indonesia sekitar $60,8 \%$, pencapaian ini masih jauh dari target yang ditetapkan yaitu $70 \%$ (Kemenkes RI, 2017). Profil kesehatan provinsi Riau tahun 2017, provinsi Riau merupakan salah satu provinsi yang pencapaian PHBS nya terendah di Indonesia yaitu sekitar 47,5 $\%$ dalam kategori jamban tidak sehat (Dinkes, 2017). Pencapaian tersebut dapat ditingkatkan melalui pemberdayaan masyarakat yang dimulai dari rumah tangga atau keluarga, karena rumah tangga yang sehat merupakan aset atau modal pembangunan yang perlu dijaga, ditingkatkan dan dilindungi kesehatannya.

Pemberdayaan masyarakat merupakan ujung tombak untuk promosi kesehatan dan berpengaruh terhadap perilaku hidup bersih sehat (Patilaiya $\mathrm{H}$ and Rahman H, 2018). Promosi kesehatan berpengaruh terhadap perubahan perilaku penimbangan bayi setiap bulan, mencuci tangan, penggunaan air bersih, penggunaan jamban sehat, pemberantasan jentik nyamuk, konsumsi buah dan sayur, melakukan aktifitas fisik dan tidak merokok (Lubis AH, 2019). Indikator PHBS dalam tatanan rumah tangga yaitu: (1) Pertolongan persalinan oleh tenaga kesehatan, (2) Bayi diberi ASI eksklusif, (3) Menimbang bayi dan balita setiap bulan, (4) Ketersediaan air bersih, (5) Mencuci tangan dengan air bersih yang mengalir dan sabun, (6) Ketersediaan jamban sehat, (7) Memberantas jentik di rumah sekali seminggu, (8) Makan buah dan sayur setiap hari, (9) Melakukan aktifitas fisik setiap hari, (10) Tidak merokok di dalam rumah. Keberhasilan program Keberhasilan PHBS dibagi menjadi 4 tingkatan dan kategori : Sehat I, Sehat II, Sehat III, Sehat IV, dengan target pemerintah yaitu tercapainya penduduk Indonesia yang ber-PHBS pada tingkat Sehat IV (Ningsih FG and Jonyanis, 2019) Penerapan PHBS tidak hanya perlu ditanamkan dalam lingkup keluarga, namun disemua sektor kegiatan dan wilayah. Tidak hanya pada lingkungan perkotaan, pedesaan, lingkungan perumahan namun juga di tempat-tempat lain seperti halnya Tempat Pembuangan Akhir sampah.

Tempat Pembuangan Akhir sampah (TPA) Muara Fajar Kecamatan Rumbai Pekanbaru merupakan tempat pemprosesan akhir sampah yang berasal dari semua kecamatan yang ada di Pekanbaru. Sampah yang masuk setiap harinya diperkirakan 400-450 ton, yang didalamnya terdapat berbagai jenis sampah seperti sampah rumah tangga, sampah bongkaran bangunan, sampah dari tempat komersil dan sebagainya. Perumahan penduduk berada disekeliling TPA, yang sebagian besar masyarakatnya bekerja sebagai pemulung dan dominan wanita (Ertawati, 2015). Fakta di lapangan masih banyak pemulung tidak mencuci tangan setelah beraktivitas, tidak membersihkan diri dulu dan mengganti pakaian saat makan. Kebiasaan ini beresiko rentan tertular penyakit pencernaan seperti diare, cacingan bahkan jika terjadi pada wanita hamil beresiko terjadinya komplikasi kehamilan. Wanita sebagai penentu dalam rumah tangga yang merupakan aset pembangunan dan pendidik utama dalam keluarga diharapkan mampu berperan mensejahterakan keluarga melalui perilaku hidup bersih sehat, berperan sebagai role model keluarga dalam berprilaku PHBS, terutama anggota keluarga yang rentan tertular penyakit menular dan tidak menular maupun wanita untuk persiapan reproduksi.Perilaku hidup bersih sehat harus dipraktikkan dalam kehidupan sehari-hari dan dapat menjadi pola kebiasaan kehidupan, dengan melibatkan seluruh anggota keluarga (Anggraini DT dan Hasibuan R, 2020)

Pemberdayaan berhasil jika dilaksanakan melalui kemitraan serta menggunakan metode dan teknik yang tepat. Pemberdayaan masyarakat melalui kemitraan dapat dilakukan melalui posyandu, menggerakkan kader dalam masyarakat, serta bekerjasama dengan organisasi atau Lembaga 
Swadaya Masyarakat (LSM) yang bergerak dalam bidang kesehatan atau peduli kesehatan, agar pemberdayaan masyarakat berdayaguna dan berhasilguna (Hidayah N; Marwan; Rahmawati DL, 2020)

Perlu adanya pemberdayaan masyarakat untuk menunjang tertibnya penerapan PHBS pada masyarakat. Keberhasilan pemberdayaan masyarakat dapat dievaluasi dari kegiatan posyandu, adanya kader dan organisasi kesehatan yang ada dalam masyarakat. Penelitian sebelumnya merupakan penelitian explanatory research yang membahas pengaruh promosi kesehatan terhadap tingkat perilaku hidup bersih sehat tanpa melihat perbandingan peran kader, posyandu dan organisasi terhadap PHBS. Tujuan penelitian ini adalah Mengetahui pengaruh pemberdayaan masyarakat berbasis keluarga melalui posyandu, kader, pengorganisasian/kelompok kesehatan dalam hubungannya dengan Perilaku Hidup Bersih Sehat di TPA Muara Fajar Rumbai Pekanbaru.

\section{Metodologi Penelitian}

Jenis penelitian adalah penelitian observasional dengan pendekatan Cross Sectional yang dilakukan TPA RT 01/RW 03 Kelurahan Muara Fajar Kecamatan Rumbai Pekanbaru. Penelitian dilakukan setelah mendapat persetujuan dari Kelurahan Muara Fajar dengan nomor 40/KelMF/XII/2019. Subjek penelitian adalah semua ibu Rumah Tangga di TPA RT 01/RW 03 sebanyak 26 responden, dengan menggunakan tekhnik Total Sampling. Instrumen yang digunakan adalah kuesioner. Kuesioner yang digunakan kuesioner standar yang sudah pernah diujikan di penelitian terdahulu (Lubis AH, 2019). Hasil uji menunjukkan gerakan pemberdayaan masyarakat melalui posyandu, kader dan pengorganisasian/kelompok adalah valid $r$ hitung > 0,366 . Pengumpulan data dilakukan oleh peneliti dibantu oleh 1 orang enumerator dengan pendidikan diploma III Analis Kesehatan, penelitian dengan melakukan wawancara dengan responden. Variabel independen yaitu Pemberdayaan masyarakat berbasis keluarga melalui posyandu, kader dan kelompok, sedangkan variabel dependen adalah perilaku hidup bersih sehat yang merujuk pada indikator tidak sehat, sehat I, sehat II, sehat III, sehat IV. Kategori tidak sehat jika tidak memenuhi 10 indikator PHBS, sehat I jika terpenuhi hanya 1-3 indikator PHBS, sehat II keadaan terpenuhi 4-6 indikator PHBS, sehat III jika terpenuhi 7 sampai 9 indikator PHBS, dan sehat IV jika terpenuhi 7 sampai 9 indikator PHBS.. Kuesioner pemberdayaan masyarakat mencakup penanganan dan informasi tentang kesehatan ibu dan anak, pelayanan posyandu terhadap PHBS, peran kader kesehatan, peran organisasi dalam masyarakat, peran organisasi kesehatan terhadap PHBS. Analisis bivariat untuk mengetahui pengaruh pemberdayaan masyarakat berbasis keluarga melalui posyandu, kader, pengorganisasian/kelompok kesehatan dalam hubungannya dengan Perilaku Hidup Bersih Sehat dengan menggunakan uji korelasi Pearson dan regresi linier.

\section{Hasil dan Pembahasan}

Berdasarkan hasil penelitian, diketahui karakteristik responden adalah sebagai berikut:

Tabel 1: Karakteristik Responden $(\mathbf{n}=\mathbf{2 6})$

\begin{tabular}{ccc}
\hline Variabel & $\mathrm{n}$ & $\%$ \\
\hline Usia Ibu & & \\
$20-24$ & 2 & 7,7 \\
$25-29$ & 6 & 23,1 \\
$30-34$ & 6 & 23,1 \\
$35-39$ & 9 & 34,6 \\
$40-44$ & 3 & 11,5 \\
\hline
\end{tabular}

\section{Pendacapaian Indikator \\ PHBS}

\begin{tabular}{|c|c|c|}
\hline Tidak Sehat & 0 & 0 \\
\hline Sehat I & 1 & 3,9 \\
\hline Sehat II & 2 & 7,7 \\
\hline Sehat III & 7 & 26,9 \\
\hline Sehat IV & 16 & 61,5 \\
\hline otal & 26 & 100 \\
\hline
\end{tabular}

menunjukkan bahwa sebagian besar responden berada dalam kelompok umur 35-39 tahun $(34,6 \%)$. Kategori PHBS sehat IV $(61,5 \%)$, sehat III $(26,9 \%)$, sehat II $(7,7 \%)$ dan sehat $1(3,9 \%)$. Lebih lanjut Tabel 2 menunjukkan bahwa pemberdayaan masyarakat berbasis keluarga melalui posyandu $(\mathrm{p}=0,081)$, kader $(\mathrm{p}=0,020)$, pengorganisasian/kelompok $\quad(\mathrm{p}=0,493)$. Pemberdayaan masyarakat berbasis keluarga melalui kader berpengaruh signifikan terhadap perilaku hidup bersih sehat $(\mathrm{p}<0,05)$. Korelasi pemberdayaan masyarakat berbasis keluarga melalui kader terhadap perilaku hidup bersih sehat sebesar $r=0,455\left(R^{2}=0,207\right)$ berpengaruh paling besar 0,206 kali dibandingkan pemberdayaan masyarakat berbasis keluarga melalui posyandu \& pengorganiasasian/kelompok 0,123 kali $\mathrm{r}=0,348$ $\left(\mathrm{R}^{2}=0,121\right)$ dan 0,024 kali $\mathrm{r}=0,141\left(\mathrm{R}^{2}=0,020\right)$. 
Faletehan Health Journal, 8 (3) (2021) 166-172

www. journal.Ippm-stikesfa.ac.id/ojs/index.php/FHJ

ISSN 2088-673X | 2597-8667

Tabel 2. Pemberdayaan masyarakat berbasis keluarga melalui posyandu, kader, pengorganisasian/kelompok terhadap Perilaku Hidup Bersih Sehat $(\mathrm{n}=26)$

\begin{tabular}{|c|c|c|c|c|}
\hline Variabel & $\mathbf{r}^{2}$ & $\mathbf{R}^{2}$ & Persamaan Garis & $\mathbf{P}$ \\
\hline $\begin{array}{llr}\text { Pemberdayaan } & \text { Masyarakat } \\
\text { Berbasis } & \text { Keluarga } & \text { Melalui } \\
\text { Posyandu } & & \\
\end{array}$ & 0,348 & 0,121 & PHBS $=3,88+0,123$ & 0,081 \\
\hline $\begin{array}{lr}\text { Pemberdayaan } & \text { Masyarakat } \\
\text { Berbasis Keluarga Melalui Kader }\end{array}$ & 0,455 & 0,207 & PHBS $=1,85+0,206$ & 0,020 \\
\hline $\begin{array}{l}\text { Pemberdayaan Masyarakat } \\
\text { Berbasis Keluarga Melalui } \\
\text { Pengorganisasian/ Kelompok }\end{array}$ & 0,141 & 0,020 & PHBS $=7,15+0,024$ & 0,493 \\
\hline
\end{tabular}

\section{Pemberdayaan Masyarakat melalui Posyandu}

Hasil analisis memberikan perkiraan bahwa apabila pemberdayaan keluarga melalui posyandu ditingkatkan, maka PHBS responden juga meningkat menjadi lebih baik. Puskesmas merupakan sarana pelayanan kesehatan terdepan untuk melaksanakan strategi promosi kesehatan dalam pembangunan kesehatan di Indonesia. Tingkat kinerja puskesmas dalam pelaksanaan strategi promosi kesehatan akan mempengaruhi tingkat pencapaian PHBS masyarakat, keluarga dan individu. Pemberdayaan masyarakat yang melibatkan fasilitas pelayanan kesehatan masyarakat, dengan melibatkan individu dan komunitas sebagai pelaku utama dapat mengurangi kesenjangan kesehatan (Thompson B ; Molina Y; Viswanath K ; Warnecke R ; Prelip ML, 2016).

Program posyandu merupakan strategi jangka panjang untuk menurunkan angka kematian bayi dan angka kematian ibu di suatu daerah. Pelayanan kesehatan yang dilaksanakan di Posyandu Muara Fajar adalah pelayanan kesehatan ibu dan anak, keluarga berencana, imunisasi dan gizi. Lembaga kesehatan yang berbasis masyarakat, sasaran primer posyandu yakni ibu hamil dan balita, sasaran sekunder terdiri dari kepala keluarga, wanita, sasaran tersier tokoh masyarakat. Terkait upaya pemberdayaan masyarakat posyandu melakukan berbagai upaya untuk meningatkan pengetahuan, kemampuan untuk cepat mengambil keputusan dan memudahkan akses terhadap pelayanan kesehatan, disamping itu posyandu dapat dimanfaatkan sebagai sarana tukar pendapat dan pengalaman serta bermusyawarah untuk memecahkan masalah yang dihadapi masyarakat. Untuk menurunkan angka kematian dan kesakitan dalam masyarakat diperlukan peran serta masyarakat dalam mengelola dan memanfaatkan posyandu karena posyandu adalah milik masyarakat, dilaksanakan oleh masyarakat dan ditujukan untuk kepentingan masyarakat (Juwita DW, 2020). Pemberdayaan menekankan bahwa orang memperoleh keterampilan, pengetahuan dan kekuasaan yang cukup untuk mempengaruhi kehidupan orang lain, dengan pemahaman bahwa pemberdayaan mengarah pada konsep partisipasi sebagaimana halnya kegiatan yang ada pada posyandu, yang menunjukkan partisipasi atau keterlibatan masyarakat berperan penting untuk mewujudkan pemberdayaan yang maksimal. Berbagai kegiatan penyuluhan kesehatan yang dilakukan di TPA Muara Fajar menyangkut PHBS seperti mencuci tangan dengan air mengalir dan sabun, memastikan ketersediaan air bersih, memberantas jentik nyamuk, posyandu menjadi wadah bagi masyarakat terutama ibu-ibu untuk melakukan kegiatan positif lainnya (Sofianis N dan Febrinia R, 2021).

Pada umumnya pemulung di TPA Muara Fajar sudah melaksanakan PHBS yang disosialisasikan oleh tenaga kesehatan melalui posyandu seperti melakukan cuci tangan setiap hari, akan tetapi belum melakukan cuci tangan yang benar, dalam artian cara melakukan cuci tangan maupun kapan harus mencuci tangan belum maksimal. Cuci tangan yang benar sebagai upaya untuk pencegahan penyakit. Kebiasaan tidak mencuci tangan sebelum menyiapkan makanan, sebelum makan, setelah beraktivitas atau mencuci tangan dengan air dalam kobokan yang biasanya dipakai bersama, atau mencuci tangan tanpa menggunakan sabun, yang dapat menyebabkan penularan penyakit diare, cacingan, disentri dan kolera. 


\section{Pemberdayaan Masyarakat Berbasis Keluarga Melalui Kader}

Hasil analisis menunjukkan bahwa pemberdayaan masyarakat berbasis keluarga melalui kader terhadap PHBS mempunyai pengaruh yang paling besar $(0,206)$ terhadap tingkat PHBS dibandingkan melalui posyandu (0.123) dan organisasi kelompok kesehatan (0.024). Peranan kader sangat penting karena kader bertanggung jawab dalam kegiatan posyandu dan PHBS, bila kader tidak aktif maka pelaksanaan posyandu juga tidak lancar yang secara langsung akan mempengaruhi tingkat keberhasilan PHBS, kader ikut berperan dalam pencapaian PHBS karena melalui kader masyarakat bisa mendapatkan informasi kesehatan lebih dahulu (Andira, 2012).

Lebih lanjut program promosi kesehatan tentang kebersihan yang dilakukan dengan memberikan pendidikan kesehatan yang berulangulang dan dalam jangka panjang dianggap efektif untuk merubah perilaku masyarakat tentang pola hidup bersih, ini dapat dilakukan oleh tokoh masyarakat yang dianggap paling sering kontak dengan masyarakat melalui kader. Keberhasilan kesehatan membutuhkan keterlibatan masyarakat yang berkelanjutan yang juga bergantung pada keberlanjutan program (Rifkin, 2014). Jurnal yang berjudul "Analisis Promosi Kesehatan Di Puskesmas Kalijudan Terhadap PHBS Rumah Tangga, peran promosi kesehatan puskesmas dalam capaian PHBS dapat diwujudkan melalui serangkaian program promosi kesehatan yaitu kunjungan rumah, pemberdayaan melalui kemitraan, serta pengorganisasian melalui upaya kesehatan berbasis masyarakat (Sari IIK; Sulistyowati M, 2015)

Posyandu masing-masing memiliki kader kesehatan yang melayani pelayanan kesehatan ibu, anak dan masyarakat. Di TPA RT 01/RW 03 Muara Fajar Rumbai Pekanbaru terdapat 5 anggota kader. Kehadiran kader di tiap kegiatan posyandu kurang maksimal, dikarenakan sebagian kader bekerja untuk membantu perekonomian keluarga. Kader sudah berpartisipasi aktif untuk mengajak masyarakat mengikuti kegiatan posyandu. Kader orang yang pertama kali dicari jika ada anggoota keluarga yang tidak sehat, jika ada masyarakat yang tidak datang ke posyandu, maka bersama tenaga kesehatan melakukan pendekatan, datang ke rumah untuk mengatasi masalah kesehatan. Peran kader sangat besar sebagai perpanjangan tangan tenaga kesehatan dalam melaporkan masalah kesehatan yang dialami masyarakat.

\section{Pemberdayaan Masyarakat Berbasis Keluarga Melalui Kesehatan Pengorganisasian/Kelompok}

Pemberdayaan masyarakat berbasis keluarga melalui pengorganisasian/kelompok kesehatan akan berpengaruh 0.024 kali terhadap perilaku hidup bersih dan sehat masyarakat. Salah satu organisasi yang telah ada dan diakui manfaatnya bagi masyarakat terutama dalam upaya meningkatkan keberdayaan dan kesejahteraan keluarga adalah gerakan Pemberdayaan dan Kesejahteraan Keluarga (PKK). Dalam PKK yang diberdayakan salah satunya adalah peningkatan kesehatan. Peran PKK diharapkan dapat mengubah prilaku masyarakat agar berprilaku hidup bersih dan sehat. PKK diharapkan tidak hanya menjadi tempat arisan dan pengajian saja melainkan sebagai wadah pemberdayaan masyarakat. Kelompok organisasi yang ada di masyarakat diharapkan dapat menjadi jembatan bagi tenaga kesehatan untuk perubahan perilaku individu, kelompok dan masyarakat sehubungan dengan pencegahan penyakit, penyembuhan penyakit dan pemulihan kesehatan (Susanti dkk, 2019).

Studi kasus didua Negara maju dan berkembang bahwa pemberdayaan masyarakat yang melibatkan partisipasi organisasi berbasis masyarakat, kepemimpinan lokal, mobilisasi sumber daya, penilaian masalah, koordinasi dengan organisasi lain, peran agen dan managemen program dapat mengarah pada peningkatan status kesehatan individu, kelompok atau komunitas (Thompson B; Molina Y; Viswanath K; Warnecke R; Prelip ML, 2016). Lebih lanjut partisipasi masyarakat secara luas diyakini bermanfaat bagi pengembangan, implementasi dan evaluasi layanan kesehatan, selain itu penelitian ini juga melaporkan banyak bukti bahwa keterlibatan masyarakat memiliki dampak positif terhadap kesehatan, terutama ketika didukung oleh proses organisasi dan masyarakat yang kuat. Efektivitas partisipasi masyarakat menghasilkan hasil positif terhadap kesehatan baik pada individu maupun kelompok organisasi masyarakat. Masyarakat membentuk komunitas kemudian berkumpul untuk mengatasi masalah komunitas yang diidentifikasi sendiri dan menciptakan perubahan positif yang mandiri, sesuai konteks kemudian transfer pengetahuan kepada masyarakat melalui sharing 
Faletehan Health Journal, 8 (3) (2021) 166-172

www. journal.Ippm-stikesfa.ac.id/ojs/index.php/FHJ

ISSN 2088-673X | 2597-8667

dan penyuluhan (Haldane, Chuah, Srivastava, Singh, Koh, Seng, 2019). Penelitian yang dilakukan di Australia tentang kesehatan primer mengidentifikasi bahwa partisipasi masyarakat mempengaruhi akses, penerimaan, ketersediaan, daya tangkap dan kualitas layanan, dengan potensi peningkatan pemanfaatan dan pada akhirnya meningkatkan hasil kesehatan (Gomersall et al., 2017).

Kelompok organisasi masyarakat yang ada di TPA Muara Fajar masih dalam bentuk majelis taklim ibu PKK, namun kelompok majelis taklim ibu PKK di tempat ini belum berfungsi sebagai wadah dalam peningkatan perilaku PHBS bagi masyarakat, majelis taklim hanya sebagai wadah arisan dan pengajian kelompok masyarakat.

\section{Simpulan}

Pemberdayaan masyarakat berbasis keluarga melalui kader berpengaruh signifikan dengan PHBS, dan berpengaruh paling besar dibandingkan pemberdayaan masyarakat berbasis keluarga melalui posyandu dan pengorganiasasian/kelompok.

\section{Referensi}

Andira, A. \& S. (2012). Faktor-faktor yang berhubungan dengan kinerja kader dalam kegiatan posyandu di Kec. Bontobahari Kabupaten Bulukumba Tahun 2012. 1-13.

Anggraini DT dan Hasibuan R. (2020). Gambaran promosi PHBS dalam mendukung gaya hidup sehat masyarakat Kota Binjai pada masa pandemic Covid-19 tahun 2020. Jurnal Menara Medika, 3(1), 22-31.

Depkes, R. (2008). Buku Saku Rumah Tangga Berprilaku Hidup Bersih dan Sehat (PHBS).

Dinkes, R. (2017). Profil Dinas Kesehatan Provinsi Riau tahun 2017.

Ertawati, I. M. and N. (2015). Sistim pengolahan limbah TPA Muara Fajar dan pengaruh terhadap kualitas air tanah disekitarnya. Jurnal Ilmu Lingkungan, 9(1), 83-95.

Gomersall, J. S., Gibson, O., Dwyer, J., O’Donnell, K., Stephenson, M., Carter, D., Canuto, K., Munn, Z., Aromataris, E., \& Brown, A. (2017). What Indigenous Australian clients value about primary health care: a systematic review of qualitative evidence. Australian and New Zealand Journal of Public Health, 41(4), 417-423. https://doi.org/10.1111/17536405.12687
Haldane, Chuah, Srivastava, Singh, Koh, Seng, et al. (2019). Community participation in health services development, implementation, and evaluation: A systematic review of empowerment, health, community, and process outcomes. European Journal of Public Health, 14(5), 1-25. https://doi.org/10.1093/eurpub/ckx187.429

Hidayah N; Marwan; Rahmawati DL. (2020). Pemberdayaan Masyarakat Melalui Gerakan Serentak PHBS Pada Tatanan Rumah Tangga. Journal of Community Engagement in Health, $3(2)$,

123-128. https://doi.org/10.30994/jceh.v3i2.47

Juwita DW. (2020). Makna Posyandu Sebagai Sarana Pembelajaran Non Formal Di Masa Pandemic Covid 19. Meretas: Jurnal Ilmu Pendidikan, 7(1), 1-15.

Kemenkes RI. (2011). Peraturan Menteri Kesehatan Republik Indonesia. Peraturan Menteri Kesehatan No. 2406 TAHUN 2011 Tentang Pedoman Pembinaan Perilaku Hidup Bersih Dan Sehat (PHBS), 4.

Kemenkes RI. (2017). Profil Kesehatan Tahun 2017.

Lubis AH. (2019). Pengaruh Promosi Kesehatan terhadap Perubahan Pengetahuan Hidup Bersih dan Sehat (PHBS) pada Tatanan Rumah Tangga di Desa Batu Godang Kecamatan Angkola Sangkunur Tahun 2019.

Ningsih FG and Jonyanis. (2019). Perilaku Hidup Bersih dan Sehat dalam Rumah Tangga (PHBS) Pada Masyarakat Desa Gunung Kesiangan, Kecamatan Benai Kabupaten Kuantan Singingi. JOM FISIP, I(2), 1-14.

Patilaiya H and Rahman H. (2018). Pemberdayaan Masyarakat Melalui Penyuluhan Perilaku Hidup Bersih dan Sehat untuk Meningkatkan Kualitas Kesehatan Masyarakat. JPPM (Jurnal Pengabdian Dan Pemberdayaan Masyarakat), 2(2), 251. https://doi.org/10.30595/jppm.v2i2.2512

Rifkin, S. B. (2014). Examining the links between community participation and health outcomes: A review of the literature. Health Policy and Planning, 29, ii98-ii106. https://doi.org/10.1093/heapol/czu076

Sari IIK ; Sulistyowati M. (2015). Analisis Promosi Kesehatan di Puskesmas Kalijudan terhadap PHBS Rumah Tangga Ibu Hamil. Jurnal PROMKES The Indonesian Journal of Health Promotion and Health Education, 3(2), 159- 
170.

https://e-

journal.unair.ac.id/PROMKES/article/view/4 $428 \% 0 \mathrm{~A}$

Sofianis N dan Febrinia R. (2021). Implementasi program pemberdayaan masyarakat melalui kegiatan posyandu terkait kesadaran hidup sehat pada masa pandemi di Desa Buatan II Kecamatan Koto Gasib. Jurnal Trias Politika, 5(1), 74-81.

Thompson B ; Molina Y ; Viswanath K ; Warnecke R; Prelip ML. (2016). Strategies To Empower Communities To Reduce Health Disparities. Health Aff (Millwood), 35(8), 1424-1428. https://doi.org/10.1016/j.physbeh.2017.03.04 0

Yuningsih, R. (2020). Promosi Kesehatan Pada Kehidupan New Normal Pandemi Covid-19. Info Singkat, XII no 11/(2088-2351), 13-18. 